\title{
Modeling Retention and Selectivity as a Function of pH and Column Temperature in Liquid Chromatography
}

\author{
Leonardo G. Gagliardi, ${ }^{\dagger}$ Cecilia B. Castells, ${ }^{\star, \ddagger}$ Clara Ràfols, ${ }^{\dagger}$ Martí Rosés, ${ }^{\dagger}$ and Elisabeth Bosch ${ }^{\dagger}$ \\ Departament de Química Analitica, Facultat de Química, Universitat de Barcelona, Barcelona, Spain, and Division Química \\ Analitica, Facultad de Ciencias Exactas, Universidad Nacional de La Plata, Buenos Aires, Argentina
}

In reversed-phase liquid chromatography (RPLC), the retention of weak acids and bases is a sigmoidal function of the mobile-phase $\mathrm{pH}$. Therefore, $\mathrm{pH}$ is a key chromatographic variable to optimize retention and selectivity. Furthermore, at an eluent $\mathrm{pH}$ close to the $\mathrm{p} K_{\mathrm{a}}$ of the solute, the dependence of ionization of the buffer and solute on temperature can be used to improve chromatographic separations involving ionizable solutes by an adequate handling of column temperature. In this paper, we derive a general equation for the prediction of the retentive behavior of ionizable compounds upon simultaneous changes in mobile-phase $\mathrm{pH}$ and column temperature. Four experiments, two limiting $\mathrm{pH}$ values and two temperatures, provide the input data that allow predictions in the whole range of these two variables, based on the thermodynamic fundamentals of the involved equilibria. Also, the study demonstrates the significant role that the choice of the buffer compound would have on selectivity factors in RPLC at temperatures higher than $25^{\circ} \mathrm{C}$.

One of the aims in chromatographic method development is the search for optimum experimental conditions improving separations. ${ }^{1}$ This implies the search of a compromise between an appropriate resolution of those compounds of interest within the shortest analysis time. The most common approach to achieve these optimum conditions consists of trial and error after a number of consecutive experiments. In reversed-phase liquid chromatography (RPLC) mode, another frequent strategy consists of acquiring experimental data covering a given range of the experimental parameters that are involved in the separation and, then, in selecting the optimum experimental variables that satisfy the aims of resolution and analysis time. This is usually carried out with the help of some convenient chromatographic software.,33

Another approach consists of comprehensively studying the fundamental effects that the variations of the most relevant

\footnotetext{
* Corresponding author. Fax: (+54) 2214254533. E-mail: castells@ isis.unlp.edu.ar.

$\dagger$ Universitat de Barcelona.

¥ Universidad Nacional de La Plata.

(1) Schoenmakers, P. J. Optimization of Chromatographic Selectivity: A Guide to Method Development; Elsevier: Amsterdam, 1986.

(2) Lewis, J. A.; Lommen, D. C.; Raddatz, W. D.; Dolan, J. W.; Snyder, L. R. J. Chromatogr., A 1992, 592, 183-195.

(3) Goga-Remont, S.; Heinisch, S.; Rocca, J. L. J. Chromatogr., A 2000, 868, $13-29$.

experimental variables have on the equilibria responsible for retention. This different strategy can easily lead to an accurate prediction of retention and separation factors after modifying one or more experimental parameters. The logical advantage of this approach over the former ones is that it results in equations thermodynamically consistent. On the contrary, equations can be very complicated when other side equilibria different from hydrophobic retention are simultaneously present.

Nowadays, the influence of variables such as mobile-phase type, composition, or stationary-phase hydrophobic surface on the thermodynamics of retention of neutral molecules is well understood, ${ }^{4-10}$ but the same does not hold for weak electrolytes. For the reversed-phase separation of ionizable compounds, the starting point is usually the optimization of the mobile-phase $\mathrm{pH}$. Models predicting the sigmoidal dependence between $\ln k$ as a function of $\mathrm{pH}$ with an inflection point that should correspond to the $\mathrm{p} K_{\mathrm{a}}$ of the solute have been theoretical proposed and experimentally corroborated. ${ }^{11-15}$ All these studies were carried out under isothermal conditions. However, in an RPLC chromatographic system and at an eluent $\mathrm{pH}$ close to the $\mathrm{p} K_{\mathrm{a}}$ of the solute, the dependence of ionization of both buffer acid component and solute on temperature might be used to develop and improve separations involving ionizable solutes by an adequate adjustment of column temperature. There are only a few studies about the optimization of temperature upon the separation of ionizable compounds. ${ }^{16-25}$ In the late 1970 s, Horvath published a series of

(4) Melander, W.; Campbell, D. E.; Horváth, C. J. Chromatogr. 1978, 158, 215225 .

(5) Vigh, G.; Varga-Puchony, Z. J. Chromatogr. 1980, 196, 1-9.

(6) Cole, L. A.; Dorsey, J. G. Anal. Chem. 1992, 64, 1324-1327.

(7) Cole, L. A.; Dorsey, J. G. Anal. Chem. 1992, 64, 1317-1323.

(8) Alvarez-Zepeda, A.; Barman, B. N.; Martire, D. E. Anal. Chem. 1992, 64, 1978-1984.

(9) Li, J.; Carr, P. W. Anal. Chem. 1997, 69, 2202-2206.

(10) Ranatunga, R. P. J.; Carr, P. W. Anal. Chem. 2000, 72, 5679-5692.

(11) Horváth, C.; Melander, W.; Molnár, I. Anal. Chem. 1977, 49, 142-154.

(12) Schoenmakers, P. J.; Tijssen, R. J. Chromatogr., A 1993, 656, 577-590.

(13) Rosés, M.; Canals, I.; Allemann, H.; Siigur, K.; Bosch, E. Anal. Chem. 1996, 68, 4094-4100.

(14) Sykora, D.; Tesarova, E.; Popl, M. J. Chromatogr., A 1997, 758, 37-51.

(15) Janos, P.; Skoda, J. J. Chromatogr., A 1999, 859, 1-12.

(16) Melander, W. R.; Stoveken, J.; Horváth, C. J. Chromatogr. 1979, 185, 111127.

(17) Zhu, P. L.; Dolan, J. W.; Snyder, L. R.; Hill, D. W.; Heukelem, L. V.; Waeghe, T. J. J. Chromatogr., A 1996, 756, 51-62.

(18) Li, J. Anal. Chim. Acta 1998, 369, 21-37.

(19) McCalley, D. V. J. Chromatogr., A 2000, 902, 311-321.

(20) Tran, J. V.; Molander, P.; Greibrokk, T.; Lundanes, E. J. Sep. Sci. 2001, $24,930-940$. 
fundamental papers dealing with secondary equilibria in RPLC, revealing the important influence that temperature can have on the dissociation of the buffer and, consequently, on the analyte retention. $4,11,16,26,27$ Only a few of the subsequent studies discuss the thermodynamic fundamentals associated with the two combined effects of $\mathrm{pH}$ and temperature. Li published a thorough theoretical analysis of the influence of temperature on the selectivity for different ionizable compounds, including weak monoprotic acids and bases..$^{18}$ His theoretical study concluded that it is possible that an improvement in selectivity is obtained at higher temperature for both carboxylic acids and amines at eluents buffered at high $\mathrm{pH}$.

Our goal is to evaluate the combined effect of $\mathrm{pH}$ and temperature on the retention and selectivity of various ionizable compounds when they are eluted using buffers of different chemical nature in the usual RPLC mobile phases and by considering a single hydrophobic retention mechanism. In this paper, we deduce simple equations for the description of the retention behavior of different groups of ionizable compounds including amines, carboxylic acids, and phenols on a typical hydrophobic column and using methanol/water and acetonitrile/ water mixtures covering a wide range of eluent $\mathrm{pHs}$ and column temperatures. The proposed equation describes accurately the retention of these ionizable compounds based on the experimental measurements of the limiting retention factors at two temperatures besides the knowledge of the basic dissociation thermodynamics of the used buffer and of the compounds of interest.

\section{THEORY}

The theoretical sigmoidal function describing the retention factor of ionizable compounds with $\mathrm{pH}$ was first proposed by Horváth ${ }^{11}$ and lately verified experimentally by several authors. ${ }^{14,28-32}$ Thus, the retention factor of a monoprotic solute, HA, with an acid-base equilibrium ruled by an acidity constant $K_{\mathrm{a}(\mathrm{an})}$, is strongly dependent on the mobile-phase $\mathrm{pH}$ according to

$$
k=\frac{k_{\mathrm{HA}}+k_{\mathrm{A}} 10^{\left(\mathrm{pH}-\mathrm{p} K_{\mathrm{a}(\mathrm{an})}\right)}}{1+10^{\left(\mathrm{pH}-\mathrm{p} K_{\mathrm{a}(\mathrm{an})}\right)}}
$$

In this function, $k_{\mathrm{HA}}=\varphi K_{\mathrm{HA}}$ and $k_{\mathrm{A}}=\varphi K_{\mathrm{A}}$ represent the limiting retention factors of the protonated and the dissociated

(21) Wilson, N. S.; Nelson, M. D.; Dolan, J. W.; Snyder, L. R.; Carr, P. W. J. Chromatogr., A 2002, 961, 195-215.

(22) Greibrokk, T.; Andersen, T. J. Chromatogr., A 2003, 1000, 743-755.

(23) Castells, C. B.; Gagliardi, L. G.; Ràfols, C.; Rosés, M.; Bosch, E. J. Chromatogr., A 2004, 1042, 23-35.

(24) Guillarme, D.; Heinisch, S.; Rocca, J. L. J. Chromatogr., A 2004, 1052, 39 51.

(25) Gagliardi, L. G.; Castells, C. B.; Ràfols, C.; Rosés, M.; Bosch, E. J. Chromatogr., A 2005, 1077, 159-169.

(26) Horváth, C.; Melander, W.; Molnár, I.; Molnar, P. Anal. Chem. 1977, 49, 2295-2305.

(27) Melander, W.; Chen, B. K.; Horváth, C. J. Chromatogr. 1979, 185, 99109.

(28) Schoenmakers, P. J.; van Molle, S.; Hayes, C. M. G.; Uunk, L. G. M. Anal. Chim. Acta 1991, 250, 1-19.

(29) Espinosa, S.; Bosch, E.; Rosés, M. Anal. Chem. 2000, 72, 5193-5200.

(30) Canals, I.; Portal, J. A.; Bosch, E.; Rosés, M. Anal. Chem. 2000, 72, 18021809.

(31) Bergés, R.; Sanz-Nebot, V.; Barbosa, J. J. Chromatogr., A 2000, 869, 2739.

(32) Rosés, M.; Bosch, E. J. Chromatogr., A 2002, 982, 1-30. forms of the analyte, respectively, $\varphi$ is the phase ratio (volume ratio between stationary and mobile phases), and $K_{\mathrm{I}}$ are the equilibrium constants for the transfer of solute $i$ between mobile and stationary phase. The standard states for both analyte and buffer are referred to the solutes infinitely diluted in the corresponding solvent mixture at the same temperature. By following the nomenclature recommended by IUPAC ${ }^{30,33}$ for these quantities, $\mathrm{pH}$ and $\mathrm{p} K_{\mathrm{a}}$ in eq 1 represents ${ }_{\mathrm{s}}^{\mathrm{s}} \mathrm{pH}$ and ${ }_{\mathrm{s}}^{\mathrm{s}} \mathrm{p} K_{\mathrm{a}}$, respectively.

Equation 1 can be rewritten as

$$
k=\frac{k_{\mathrm{HA}}+k_{\mathrm{A}} w}{1+w}
$$

where $w=10^{\left(\mathrm{pH}-\mathrm{p} K_{\mathrm{a}(\mathrm{an})}\right)}$. This expression applies whenever the dominant retention mechanisms between the analyte and the stationary phase are due to hydrophobic or dispersive interactions. Experimental data will not fit to this function if interactions of other origin (for instance, exclusion or ion exchange) are also involved in the chromatographic retention process.

A change in column temperature will affect all terms of eq 2: transfers of A and HA from the eluent to the stationary surface and also the dissociation constants of both analyte and buffer and, as a consequence, the mobile-phase $\mathrm{pH}$. The effect of temperature on all these equilibrium processes can be explicitly taken into account through the thermodynamic (partial molar) standard enthalpies of transfer $\Delta_{\mathrm{t}} H_{\mathrm{HA}}^{\mathrm{O}}$ and $\Delta_{\mathrm{t}} H_{\mathrm{A}}^{\mathrm{o}}$ for $\mathrm{HA}$ and $\mathrm{A}$, respectively, along with the standard enthalpies for the dissociation of the analyte, $\Delta H_{\mathrm{a}(\mathrm{an})}^{\mathrm{o}}$, and of the buffer, $\Delta H_{\mathrm{a} \text { (buff) }}^{\mathrm{o}}$, respectively. The relative weight of these four thermodynamic quantities rules the final dependence of retention factor with temperature. Three main assumptions are considered in the following analysis. First, the standard enthalpies and entropies associated with each equilibrium process are temperature independent within the studied temperature range. Second, the phase ratio, $\varphi$, is unaffected by temperature. Third, temperature dependence of the logarithm of activity coefficients ratio for molecular and ionic species is neglected (see below). In this context, van't Hoff equations can be used to express the function between any equilibrium constant and temperature:

$$
-R \frac{\partial \ln K}{\partial(1 / T)}=\Delta H^{\mathrm{o}}
$$

Then, the following definite integrals between the limits of a temperature $T$ and a reference $T_{\mathrm{r}}$ can be obtained:

$$
\ln k_{\mathrm{HA}}(T)-\ln k_{\mathrm{HA}}\left(T_{\mathrm{r}}\right)=-\left(\Delta_{\mathrm{t}} H_{\mathrm{HA}}^{\mathrm{o}} / R\right)\left[T^{-1}-T_{\mathrm{r}}^{-1}\right]
$$

or

$$
\begin{array}{r}
k_{\mathrm{HA}}(T)=k_{\mathrm{HA}}\left(T_{\mathrm{r}}\right) \exp \left\{\left(-\Delta_{t} H_{\mathrm{HA}}^{\mathrm{o}} / R\right)\left[T^{-1}-T_{\mathrm{r}}^{-1}\right]\right\} \equiv \\
k_{\mathrm{HA}}\left(T_{\mathrm{r}}\right) \Delta k_{\mathrm{HA}}
\end{array}
$$

where $\Delta k_{\mathrm{HA}}$ summarized the exponential term involving the

(33) IUPAC. Compendium on Analytical Nomenclature. Definitive Rules 1997, 3rd ed.: Blackwell Science: Oxford, UK, 1998.

Analytical Chemistry, Vol. 78, No. 16, August 15, 2006 
standard enthalpy of transfer. Similarly, for the retention of the unprotonated form of the analyte

$$
k_{\mathrm{A}}(T)=k_{\mathrm{A}}\left(T_{\mathrm{r}}\right) \exp \left\{\left(-\Delta_{\mathrm{t}} H_{\mathrm{A}}^{\mathrm{o}} / R\right)\left[T^{-1}-T_{\mathrm{r}}^{-1}\right]\right\} \equiv k_{\mathrm{A}}\left(T_{r}\right) \Delta k_{\mathrm{A}}
$$

The expressions obtained for the dissociation equilibria of the analyte and buffer component are, respectively

$$
K_{\mathrm{a}(\mathrm{an})}(T)=K_{\mathrm{a}(\mathrm{an})}\left(T_{\mathrm{r}}\right) \exp \left\{\left(-\Delta H_{\mathrm{a}(\mathrm{an})}^{\mathrm{o}} / R\right)\left[T^{-1}-T_{\mathrm{r}}^{-1}\right]\right\}
$$

and

$$
K_{\mathrm{a}(\text { buff })}(T)=K_{\mathrm{a}(\text { buff })}\left(T_{\mathrm{r}}\right) \exp \left\{\left(-\Delta H_{\mathrm{a}(\text { buff }}^{\mathrm{o}} / R\right)\left[T^{-1}-T_{\mathrm{r}}^{-1}\right]\right\}
$$

where $K_{\mathrm{a}(\text { buff }}$ represents the acidity constant of the compound used to prepare the buffer solution. Considering that both components of the buffer are relatively concentrated and that the controlled $\mathrm{pH}$ is far from 0 and from the $\mathrm{p} K_{\mathrm{ap}}$ ( $K_{\mathrm{ap}}$ is the autoprotolysis equilibrium constant of the solvent), the relationship between $\mathrm{p} K_{\mathrm{a}}$ and $\mathrm{pH}$ is given by

$$
\mathrm{p} K_{\mathrm{a}}=\mathrm{pH}-\log \left(\frac{a_{\mathrm{B}}}{a_{\mathrm{HB}}}\right)
$$

where $a_{\mathrm{B}}$ and $a_{\mathrm{HB}}$ represent the activities of the components of the conjugated pair. We assume that the change of the second term on the right-hand side of eq 9 with temperature is negligible and so the $\mathrm{pH}$ depends on temperature in the same manner as the $\mathrm{p} K_{\mathrm{a}}$. Then, eq 8 can be transformed into

$$
\mathrm{pH}(T)=\mathrm{pH}\left(T_{\mathrm{r}}\right)+\left(\Delta H_{\mathrm{a}(\text { buff })}^{\mathrm{o}} / 2.303 R\right)\left[T^{-1}-T_{\mathrm{r}}^{-1}\right]
$$

Finally, by combining (7) and (10) after applying decimal logarithm

$$
\begin{aligned}
& \mathrm{pH}(T)-\mathrm{p} K_{\mathrm{a}(\text { an })}(T)=\mathrm{pH}\left(T_{\mathrm{r}}\right)-\mathrm{p} K_{\mathrm{a}(\text { an })}\left(T_{\mathrm{r}}\right)+ \\
&\left(\Delta H_{\mathrm{a}(\text { buff })}^{\mathrm{o}}-\Delta H_{\mathrm{a}(\text { an })}^{\mathrm{o}}\right)(2.303 R)^{-1}\left[T^{-1}-T_{\mathrm{r}}^{-1}\right]
\end{aligned}
$$

and then

$$
w=10^{\left(\mathrm{pH}-\mathrm{p} K_{\mathrm{a}}\right)} \equiv w\left(T_{\mathrm{r}}\right) \Delta w
$$

where $w\left(T_{\mathrm{r}}\right)$ and $\Delta w$ are defined as follows:

$$
\begin{gathered}
w\left(T_{\mathrm{r}}\right)=10^{\left(\mathrm{pH}\left(T_{\mathrm{r}}\right)-\mathrm{p} K_{\mathrm{a}}\left(T_{\mathrm{r}}\right)\right)} \\
\Delta w=10^{\left(\Delta H_{\mathrm{a}(\mathrm{buff})}^{\mathrm{o}}-\Delta H_{\mathrm{a}(\mathrm{an})}^{\mathrm{o}}\right)(2.303 R)^{-1}\left[T^{-1}-T_{\mathrm{r}}^{-1}\right]}
\end{gathered}
$$

Finally, introducing expressions 5, 6, and 12 into eq 2, we arrive at an equation for the retention factors at any temperature and eluent $\mathrm{pH}$ can be estimated from values at a given reference temperature:

$$
k(T)=\frac{k_{\mathrm{HA}}\left(T_{\mathrm{r}}\right) \Delta k_{\mathrm{HA}}+k_{\mathrm{A}}\left(T_{\mathrm{r}}\right) \Delta k_{\mathrm{A}} w\left(T_{\mathrm{r}}\right) \Delta w}{1+w\left(T_{\mathrm{r}}\right) \Delta w}
$$

As $T$ equals $T_{\mathrm{r}}$, eq 15 reduces to the sigmoidal function given by eq 2. Expression 15 was tested in the prediction of the trend in the retentive behavior of ionogenic solutes in a mobile-phase system containing a buffer upon changes of both eluent $\mathrm{pH}$ and column temperature. Any change in the column temperature will affect the three terms: $\Delta k_{\mathrm{HA}}, \Delta k_{\mathrm{A}}$, and $\Delta w$. In these expressions, as defined in eqs 5,6 , and $14, \Delta k_{\mathrm{HA}}$ and $\Delta k_{\mathrm{A}}$ are measurements of the sensitivity of the limiting retention factors to temperature changes. For typical RPLC conditions and considering that a unique partition retention mechanism (i.e., hydrophobic retention) takes place, both enthalpies of transfer would be negative. As a consequence, $\Delta k_{\mathrm{HA}}$ and $\Delta k_{\mathrm{A}}$ will be positive but less than unity, becoming closer to unity in the case that the corresponding enthalpy of transfer $\left(\Delta_{t} H_{\mathrm{HA}}^{\mathrm{o}}\right.$ or $\left.\Delta_{t} H_{\mathrm{A}}^{0}\right)$ would be negligible. In this particular case, no dependence of temperature is expected for the limiting retention factor. On the other side, $\Delta w$ represents the magnitude of the influence that the buffer will induce over retention when temperature is modified. Thus, any change in temperature will shift the eluent $\mathrm{pH}$ according to the sign and absolute value of $\Delta H_{\mathrm{a}(\text { buff) }}^{\mathrm{o}}$. Similarly, $\Delta H_{\mathrm{a}(\mathrm{an})}^{\mathrm{o}}$ will dictate the shift in the solute acid-base equilibrium due to the change in temperature. As a consequence of these two combined effects, the $\Delta w$ value would be smaller or larger than 1 , becoming null when both dissociation enthalpies would be equal. If $\Delta w>1$, and the second term dominates the numerator of eq 15, an increase in retention with temperature is highly probable.

\section{EXPERIMENTAL SECTION}

Instrumentation. A Shimadzu LC-10A instrument, equipped with helium degasser, LC-10AD pump, Sil-10A autoinjector, SPDM10A diode array detector, and a Class-LC Chemstation was used for the HPLC measurements. Detection wavelengths were 230, 254, and $280 \mathrm{~nm}$ for detecting analytes and 205 or $215 \mathrm{~nm}$ for the dead volume markers (KBr, uracil). A $150 \times 4.6 \mathrm{~mm}$ i.d. X-Terra MS-C18 column (Waters) was used for all the measurements. It has been demonstrated that this material is stable within the $\mathrm{pH}$ range $1-12.34,35$ The mobile phase was preheated into a $20-\mathrm{cm}$ stainless steel capillary tube set immediately before the column, and both were immersed in a temperature-controlled thermostatic bath. Temperature was taken with a thermometer calibrated at $\pm 0.2^{\circ} \mathrm{C}$. The $\mathrm{pH}$ measurements of mobile-phase solutions were conducted with a Schott Blueline combined glass electrode, connected to a $702 \mathrm{SM}$ Titrino $\mathrm{pH}$-meter (Metrohm) with a precision of $\pm 0.01 \mathrm{pH}$ unit.

Chemicals. The solvents used were acetonitrile HPLC-grade (99.9\%, Mallinckrodt) and water purified by a MilliQ system (Simplicity 185, Millipore). All other chemicals were reagent grade or better, and they were obtained from Fluka, Merck, Baker, and Sigma-Aldrich. All necessary safety cautions have been considered for solvent and reagent handling. Chemical waste was delivered for a proper residual treatment.

(34) Méndez, A.; Bosch, E.; Rosés, M.; Neue, U. D. J. Chromatogr., A 2003 $986,33-44$

(35) Herrero-Martinez, J. M.; Méndez, A.; Bosch, E.; Rosés, M. J. Chromatogr., A 2004, 1060, 135-145. 
Table 1. Mobile-Phase Compositions, pH Values, and Thermodynamic Quantities of the Buffer Solutions

buffer solutions

(A) $19.0 \mathrm{mM} \mathrm{H}_{3} \mathrm{PO}_{4} / 6.0 \mathrm{mM} \mathrm{KH}_{2} \mathrm{PO}_{4} / 25 \% \mathrm{ACN}$

(B) $16.4 \mathrm{mM} \mathrm{HAc} / 7.7 \mathrm{mM} \mathrm{NaAc} / 25 \% \mathrm{ACN}$

(C) $25 \mathrm{mM}$ piperazine/40.1 $\mathrm{mM} \mathrm{HCl} / 25 \% \mathrm{ACN}$

(D) $11.1 \mathrm{mM} \mathrm{KH} \mathrm{PO}_{4} / 13.9 \mathrm{mM} \mathrm{Na} \mathrm{HPO}_{4} / 25 \% \mathrm{ACN}$

(E) $25 \mathrm{mM}$ tris $/ 17.3 \mathrm{mM} \mathrm{HCl} / 25 \% \mathrm{ACN}$

(F) $39 \mathrm{mM}$ 1-aminobutane/14.5 mM HCl/25\% ACN

(G) $6.4 \mathrm{mM} \mathrm{H}_{3} \mathrm{PO}_{4} / 2.5 \mathrm{mM} \mathrm{KH}_{2} \mathrm{PO}_{4} / 50 \% \mathrm{MeOH}$

(H) $12.0 \mathrm{mM}$ piperazine/16.5 mM HCl$/ 50 \% \mathrm{MeOH}$

(I) $8.0 \mathrm{mM} \mathrm{HAc} / 2.0 \mathrm{mM} \mathrm{NaAc} / 50 \% \mathrm{MeOH}$

(J) $7.7 \mathrm{mM} \mathrm{KH}_{2} \mathrm{PO}_{4} / 5.9 \mathrm{Na}_{2} \mathrm{HPO}_{4} / 50 \% \mathrm{MeOH}$

(K) $5.0 \mathrm{mM} \mathrm{HAc} / 5.0 \mathrm{mM} \mathrm{NaAc} / 50 \% \mathrm{MeOH}$

(L) $9.1 \mathrm{mM}$ tris $/ 5.02 \mathrm{HCl}$-tris $/ 50 \% \mathrm{MeOH}$

(M) $5.7 \mathrm{mM} \mathrm{KH}_{2} \mathrm{PO}_{4} / 4.4 \mathrm{Na}_{2} \mathrm{HPO}_{4} / 50 \% \mathrm{MeOH}$

(N) $7.5 \mathrm{mM}$ 1-aminobutane/2.5 mM HCl/50\% $\mathrm{MeOH}$

\begin{tabular}{rrc} 
& \multicolumn{3}{c}{${ }_{\mathrm{s}}^{\mathrm{s}} \mathrm{pH}$} \\
\hline $25{ }^{\circ} \mathrm{C}^{a}$ & $37{ }^{\circ} \mathrm{C}$ & $50{ }^{\circ} \mathrm{C}$ \\
2.48 & 2.51 & 2.55 \\
5.01 & 5.01 & 5.01 \\
5.01 & 4.77 & 4.53 \\
7.90 & 7.88 & 7.87 \\
7.91 & 7.59 & 7.27 \\
10.76 & 10.29 & 9.87 \\
3.04 & 3.05 & 3.09 \\
5.04 & 4.80 & 4.56 \\
5.05 & 5.06 & 5.09 \\
8.13 & 8.12 & 8.11 \\
5.64 & 5.66 & 5.68 \\
8.09 & 7.77 & 7.50 \\
8.10 & 8.09 & 8.07 \\
10.30 & 9.87 & 9.51
\end{tabular}

$\Delta H_{\mathrm{a} \text { (buff) }}^{\mathrm{o}}$

$\left(\mathrm{kJ} \cdot \mathrm{mol}^{-1}\right)$

$-6.3$

$-0.34$

37.2

3.05

47

62.3

$-4.56$

35.8

$-0.21$

1.9

$-0.21$

47.8

1.9

58.4

${ }^{a}$ Obtained from the measured ${ }_{\mathrm{w}}^{\mathrm{s}} \mathrm{pH}\left(25^{\circ} \mathrm{C}\right)$ values. ${ }^{b}$ From refs 23,25 , and 37.

Procedure. Mobile-phase solutions were prepared by premixing the buffer with a fixed acetonitrile composition of $25 \%(\mathrm{w} /$ w) or methanol composition of $50 \%(\mathrm{w} / \mathrm{w})$. Buffer solutions were prepared at these solvent compositions in the molal scale by mixing the corresponding reagents. The electrode system was calibrated using the usual aqueous standard buffers, ${ }^{36}$ thus, the ${ }_{\mathrm{w}}^{\mathrm{s}} \mathrm{pH}$ measurements were made in the aqueous-organic mobilephase mixtures. Finally, ${ }_{\mathrm{s}}^{\mathrm{s}} \mathrm{pH}$ has been obtained from subtraction of the relevant $\delta$-value from the experimental ${ }_{\mathrm{w}}^{\mathrm{s}} \mathrm{pH} .{ }^{29,37}$ This $\delta$-value, which includes the primary medium effect for hydrogen ion and the difference of the liquid-junction potentials between the two solvents expressed in $\mathrm{pH}$ units, represents the difference between the two $\mathrm{pH}$ scales. Previous measurement has shown that this $\delta$-value was practically independent of temperature for $50 \%(\mathrm{w} / \mathrm{w})$ methanol in water, ${ }^{37}$ and the same was obtained for $25 \%(\mathrm{w} / \mathrm{w})$ acetonitrile. ${ }^{38}$ Buffer concentrations, and the ${ }_{\mathrm{s}}^{\mathrm{s}} \mathrm{pH}$ at 25,37 , and $50^{\circ} \mathrm{C}$ which were calculated from the measured ${ }_{\mathrm{w}}^{\mathrm{s}} \mathrm{pH}$ at $25^{\circ} \mathrm{C}$ are reported in Table 1 . The chromatographic measurements were conducted after keeping the column at the corresponding temperature for at least $1 \mathrm{~h}$ before injection. The eluent flow rate was $1 \mathrm{~mL} / \mathrm{min}$, and the injection volume was $5 \mu \mathrm{L}$. The hold-up time was measured with potassium bromide or uracil. Solute retention factors, $k_{\mathrm{l}}$, were calculated by taking into account the extracolumn contributions to retention, and since early-eluted peaks were slightly tailed, the extracolumn and also the hold-up times were computed from calculation of the first statistical moment. All results are the average of triplicate injections.

Data Treatment. The model-fitting calculations were performed with the SigmaPlot v4.1 curve fitter.

\section{RESULTS AND DISCUSSION}

In this work, a modeling study was carried out with the aim of accurately predicting the effects of simultaneous variations of eluent $\mathrm{pH}$ (using buffers of different chemical nature) and column temperature on the retention of a series of ionogenic compounds covering a wide range of acid-base properties.

(36) Bates, R. G. In Treatise on Analytical Chemistry; Kolthoff, I. M., Elving, P. J., Eds.; John Wiley \& Sons: New York; 1978; Vol. 1, Chapter 14.

(37) Castells, C. B.; Ràfols, C.; Rosés, M.; Bosch, E. J. Chromatogr., A 2003, 1002, 41-53.

(38) Unpublished results.
Thus, the chromatographic retention of a group of ionogenic analytes in an octadecylsilica reversed-phase column and using several buffer solutions and at several temperatures was measured. A special hydrophobic C18 column, which is prepared from a silicon organic-inorganic hybrid support, was chosen. This column has no silanol activity as demonstrated by the lack of retention of the cation $\mathrm{Li}^{+}$within the $\mathrm{pH}$ range $1-12 .{ }^{34,35}$ Mobile phases included several buffers in solvent mixtures of fixed compositions: $25.0 \%(\mathrm{w} / \mathrm{w}$ ) acetonitrile (corresponding to 29.8 (v/ v) at $25^{\circ} \mathrm{C}$ ) and $50.0 \%(\mathrm{w} / \mathrm{w})$ methanol (which corresponds to $55.8 \%(\mathrm{v} / \mathrm{v})$ at $25^{\circ} \mathrm{C}$ ). Buffer solutions and mobile-phase $\mathrm{pH}$ values are described in Table 1 . All the compounds used to prepare the buffer solutions were chosen within their optimum buffer capacities, i.e., to control the eluent $\mathrm{pH}$ within the range of their corresponding $\mathrm{p} K_{\mathrm{a}} \pm 1$ unit. This caution was quite important since, on the other hand, buffer solutions were somewhat diluted. An increase in buffer component concentrations will increase ionic strengths, and then, the change of activity coefficients with temperature should be included into eq 10 to take into account the deviation from ideality.

Solutes were selected according to their acidic dissociation constant values. Their retention factors were measured in mobile phases buffered at $\mathrm{pH}$ very close to their corresponding $\mathrm{p} K_{\mathrm{a}}$. The limiting retention factors were obtained using mobile phases buffered at $\mathrm{pH}$ values well above or well below their respective $\mathrm{p} K_{\mathrm{a}}$. It has been widely demonstrated that very good relationships between retention factors and mobile-phase $\mathrm{pH}$ are obtained if the $\mathrm{pH}$ is measured after the addition of organic solvent. ${ }^{32}$

Modeling Retention. For testing eq 15, the following input data are necessary: limiting retention factors at extreme $\mathrm{pH}$ values and measured at two column temperatures; $298.15 \mathrm{~K}$ has been chosen as the reference temperature $\left(T_{\mathrm{r}}\right)$. The other required data characterize the dissociation equilibrium for both the analyte and the components of the buffer used to control mobile-phase $\mathrm{pH}$. These data include the corresponding $\mathrm{p} K_{\mathrm{a}}$ and dissociation enthalpies in the solvent mixture. Then, from the experimental $k(T)$ values, $\Delta k_{\mathrm{HA}}$ and $\Delta k_{\mathrm{A}}$, which are related with the (usually exothermic) enthalpies of transfer between both phases, can be calculated. Typical transfer enthalpy values in reversed-phase 
Table 2. Solutes Tested in the Model and Their Corresponding Acid-Base Properties at $25{ }^{\circ} \mathrm{C}$

\begin{tabular}{|c|c|c|c|c|c|}
\hline solute & ${ }_{\mathrm{w}}^{\mathrm{w}} \mathrm{p} K_{\mathrm{a}}{ }^{a}$ & ${ }_{\mathrm{s}}^{\mathrm{s}} \mathrm{p} K_{\mathrm{a}}^{b}$ & $\stackrel{{ }_{\mathrm{s}}^{\mathrm{s}} \mathrm{p} K_{\mathrm{a}}}{\text { chromatographic }}$ & $\Delta{ }_{\mathrm{s}}^{\mathrm{s}} \mathrm{p} K_{\mathrm{a}}^{d}$ & $\begin{array}{c}\Delta H_{\mathrm{a}(\mathrm{an})}^{\mathrm{o}}{ }^{e} \\
\left(\mathrm{~kJ} \cdot \mathrm{mol}^{-1}\right)\end{array}$ \\
\hline \multicolumn{6}{|c|}{ A. Solvent Mixture: $25 \%(w / w)$ Acetonitrile/Water } \\
\hline 2,6-dinitrophenol & 3.70 & 3.72 & $3.7( \pm 0.2)$ & 0.02 & 12.55 \\
\hline benzoic acid & 4.21 & 5.05 & $4.87( \pm 0.07)$ & 0.18 & 0.60 \\
\hline 3-bromobenzoic acid & 3.81 & 4.56 & $4.32( \pm 0.08)$ & 0.24 & -0.25 \\
\hline 2-methylbenzoic acid & 3.91 & 4.64 & $4.83( \pm 0.07)$ & -0.19 & -6.27 \\
\hline 4-methylaniline & 5.08 & 4.73 & $4.8( \pm 0.1)$ & -0.07 & 31.8 \\
\hline$n$-ethylaniline & 5.12 & 4.77 & $4.96( \pm 0.09)$ & -0.19 & $50^{f}$ \\
\hline 4-ethoxyaniline & 5.24 & 4.81 & $4.98( \pm 0.07)$ & -0.17 & 35.7 \\
\hline benzimidazole & 5.48 & 4.95 & $5.02( \pm 0.06)$ & -0.07 & 38.9 \\
\hline 3-methylbenzoic acid & 4.25 & 4.98 & $5.00( \pm 0.05)$ & -0.02 & 0.29 \\
\hline cinnamic acid & 4.41 & 5.19 & $5.09( \pm 0.05)$ & 0.10 & 2.5 \\
\hline \multirow{2}{*}{ 3-aminobenzoic acid } & 3.07 & 2.54 & & & 10.7 \\
\hline & 4.79 & 5.46 & & & 17.4 \\
\hline \multirow[t]{2}{*}{ 4-aminobenzoic acid } & 2.41 & 1.86 & & & 20.8 \\
\hline & 4.85 & 5.52 & & & 2.9 \\
\hline 2-nitrophenol & 7.22 & 7.71 & $7.89( \pm 0.2)$ & -0.18 & 19.5 \\
\hline 4-nitrophenol & 7.15 & 7.81 & $7.6( \pm 0.2)$ & 0.21 & 18.95 \\
\hline codeine phosphate & 8.21 & 7.91 & $7.7( \pm 0.2)$ & 0.21 & $30^{f}$ \\
\hline \multicolumn{6}{|c|}{ B. Solvent Mixture: $50 \%(w / w)$ Methanol/Water } \\
\hline quinoline & 4.94 & 3.64 & $3.6( \pm 0.2)$ & 0.04 & 22.4 \\
\hline 2-methylaniline & 4.40 & 3.91 & $3.8( \pm 0.2)$ & 0.11 & 30.21 \\
\hline pyridine & 5.17 & 4.08 & $3.8( \pm 0.3)$ & 0.28 & 20.1 \\
\hline$N, N$-dimethylaniline & 5.15 & 4.28 & $3.9( \pm 0.2)$ & 0.38 & 28.30 \\
\hline 2,4-dinitrophenol & 4.08 & 4.51 & $3.6( \pm 0.1)$ & 0.91 & 9.4 \\
\hline 4-methylaniline & 5.08 & 4.54 & $4.3( \pm 0.2)$ & 0.24 & 31.8 \\
\hline benzimidazole & 5.48 & $4.95^{c}$ & $4.6( \pm 0.1)$ & 0.35 & $38.9^{g}$ \\
\hline 2-methylbenzoic acid & 3.91 & 5.32 & $5.11( \pm 0.08)$ & 0.21 & -6.27 \\
\hline benzoic acid & 4.21 & 5.43 & $5.12( \pm 0.07)$ & 0.31 & 0.6 \\
\hline papaverine & 6.40 & 5.62 & $5.27( \pm 0.09)$ & 0.35 & $20^{f}$ \\
\hline trazodone & 6.93 & $6.33^{c}$ & $5.95( \pm 0.07)$ & 0.38 & $30^{f}$ \\
\hline 2,6-dichlorophenol & 6.79 & 7.68 & $8.09( \pm 0.08)$ & -0.41 & $20^{f}$ \\
\hline benzyldimethylamine & 8.91 & 8.20 & $8.0( \pm 0.1)$ & 0.20 & $30^{f}$ \\
\hline 2,4-dichlorophenol & 7.85 & 8.60 & $8.9( \pm 0.2)$ & -0.30 & $20^{f}$ \\
\hline benzvlamine & 9.37 & 8.81 & $8.83(+0.09)$ & -0.02 & 55 \\
\hline
\end{tabular}

${ }^{a}$ From refs 41 and $44-48 .{ }^{b}$ From refs $25,40,47,49$, and 50. ${ }^{c}$ Unpublished results. ${ }^{d} \Delta{ }_{\mathrm{s}}^{\mathrm{s}} \mathrm{p} K_{\mathrm{a}}={ }_{\mathrm{s}}^{\mathrm{s}} \mathrm{p} K_{\mathrm{a}}-{ }_{\mathrm{s}}^{\mathrm{s}} \mathrm{p} K_{\mathrm{a}}$ (chrom) $\cdot{ }^{e}$ From refs 25 and 41. ${ }^{f}$ Estimated as $50 \mathrm{~kJ} / \mathrm{mol}$ for primary and secondary amines, $30 \mathrm{~kJ} / \mathrm{mol}$ for tertiary amines, $20 \mathrm{~kJ} / \mathrm{mol}$ for aromatic nitrogen, and $20 \mathrm{~kJ} / \mathrm{mol}$ for phenols. ${ }^{g}$ Data measured for 2-ethylbenzimidazole.

systems depend on solute size; they are about -10 to $-15 \mathrm{~kJ} \mathrm{~mol}{ }^{-1}$ for small analytes. ${ }^{22}$

In the computing, we assume the knowledge of ${ }_{\mathrm{s}}^{\mathrm{s}} \mathrm{p} K_{\mathrm{a}}$ and dissociation enthalpies of both the ionogenic substance used as a buffer as well as the assayed solutes. ${ }_{\mathrm{s}}^{\mathrm{s}} \mathrm{p} K_{\mathrm{a}}$ and $\Delta H_{\mathrm{a} \text { (buff) }}^{\mathrm{o}}$ of all compounds used to prepare the buffers were previously measured in the corresponding solvent mixture..$^{23,37}$ The values are gathered in Table 1. Acid-base properties of solutes in the hydroorganic mixtures are gathered in Table 2. These data were taken from the literature or estimated as follows. For those solutes whose ${ }_{\mathrm{s}}^{\mathrm{s}} \mathrm{p} K_{\mathrm{a}}$ were unavailable, the dissociation constants were computed through the linear relationship between ${ }_{\mathrm{s}}^{\mathrm{s}} \mathrm{p} K_{\mathrm{a}}$ and the available ${ }_{\mathrm{w}}^{\mathrm{w}} \mathrm{p} K_{\mathrm{a}}$ :

$$
{ }_{\mathrm{s}}^{\mathrm{s}} \mathrm{p} K_{\mathrm{a}}=a_{\mathrm{s} w}{ }_{\mathrm{w}}^{\mathrm{w}} \mathrm{p} K_{\mathrm{a}}+b_{\mathrm{s}}
$$

The coefficients $a_{\mathrm{s}}$ and $b_{\mathrm{s}}$ for each compound family and solvent composition were those proposed by Espinosa et al. for the acetonitrile/water mixture ${ }^{39}$ and those proposed by Rived et al. for methanol/water hydroorganic mixture. ${ }^{40}$ In both cases, the coefficients were computed from exhaustive compilations of values

(39) Espinosa, S.; Bosch, E.; Rosés, M. J. Chromatogr., A 2002, 964, 55-66. available from literature. Data of dissociation enthalpies for these substances in the usual hydroorganic mixtures used in RPLC are practically nonexistent. Our previous experience indicates that, for the binary mixtures used here, which are in the water-rich region, these standard enthalpies are similar to those measured for the same compounds in pure water. ${ }^{25,37}$ This assumption was followed here: solute dissociation enthalpies correspond to the thermodynamics quantities measured in pure water and compiled by Christensen et ll. $^{41}$ In a few cases, these quantities were estimated by analogy with other known values of similar chemical acid-base structures.

Plots of $k$ versus $\mathrm{pH}$ for each compound at five temperatures when using $25 \%(\mathrm{w} / \mathrm{w})$ acetonitrile in water and at three temperatures when using $50 \%(\mathrm{w} / \mathrm{w})$ methanol in water were computergenerated. Only some representative examples are presented and discussed from the following figures (Figures 1-5).

Figure 1 shows the predicted as well as the experimental retention factors of three carboxylic acids (benzoic, 3-methylbenzoic, and 3-bromobenzoic acids) as a function of mobile-phase $\mathrm{pH}$

(40) Rived, F.; Canals, I.; Bosch, E.; Roses, M. Anal. Chim. Acta 2001, 439, $315-333$.

(41) Christensen, J. J.; Hansen, L. D.; Izzat, R. M. Handbook of Proton Ionization Heats and Related Thermodynamic Quantities; Wiley-Interscience: New York, 1976. 

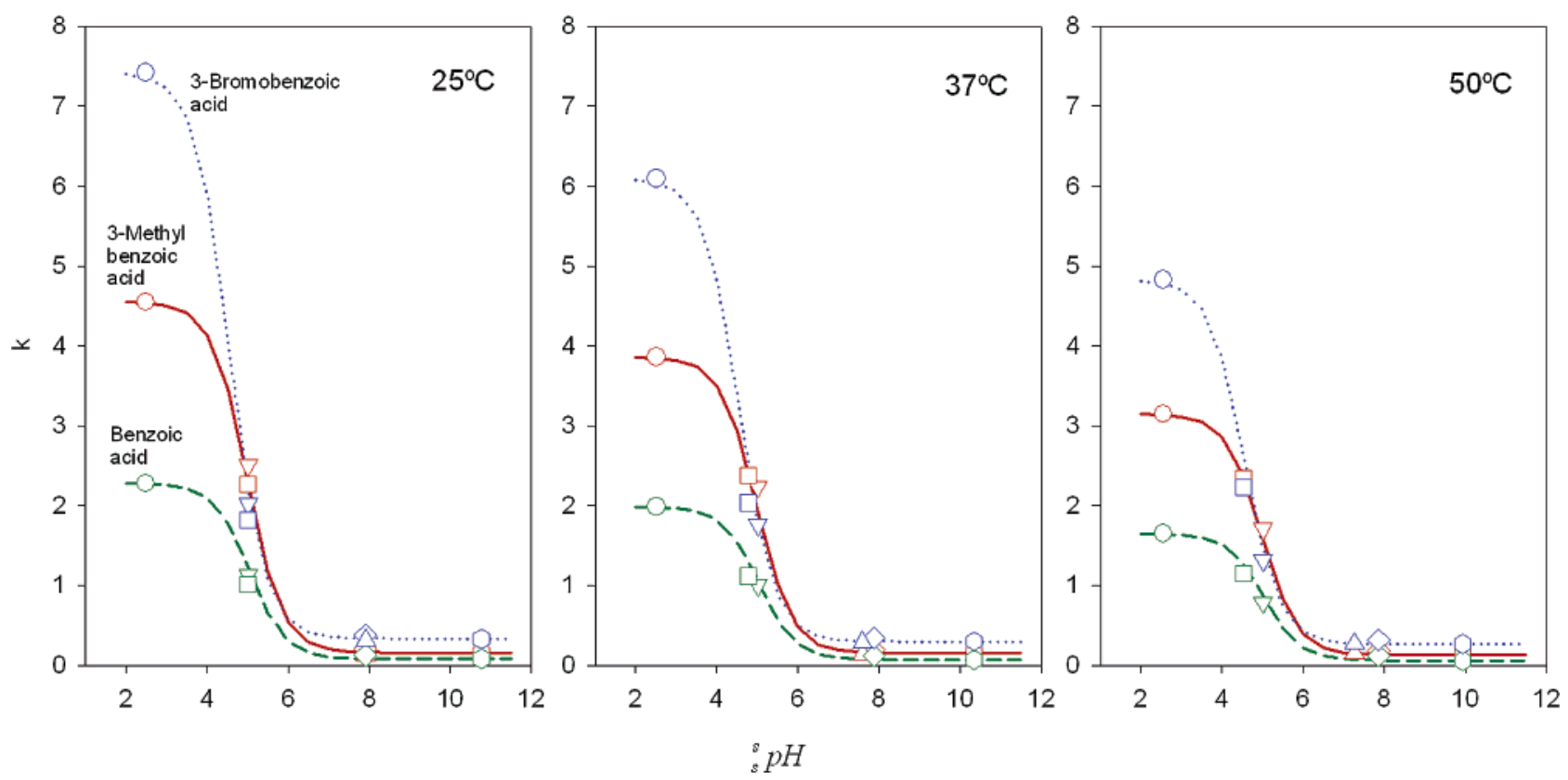

Figure 1. Experimental retention factors (points) and predicted retention factors (lines) of three carboxylic acids versus ${ }_{s}^{5} \mathrm{pH}$ at 25,37 , and 50 ${ }^{\circ} \mathrm{C}$. Column: MS X-Terra C18 $(150 \times 4.6 \mathrm{~mm}$ i.d.). Mobile phase: buffer solutions in $25 \% \mathrm{w} / \mathrm{w}$ acetonitrile/water mixture. Symbol type indicates the following buffers: circles, phosphoric acid/dihydrogen phosphate (mobile phase A, see Table 1); triangles down, acetic acid/sodium acetate (mobile phase B); squares, piperazine/hydrochloric acid (eluent C); diamonds, dihydrogen phosphate/disodium phosphate (eluent D); triangles up, tris/tris- $\mathrm{HCl}$ (eluent $\mathrm{E}$ ); hexagons: butylamine/ $\mathrm{HCl}$ (buffer $\mathrm{F}$ ).
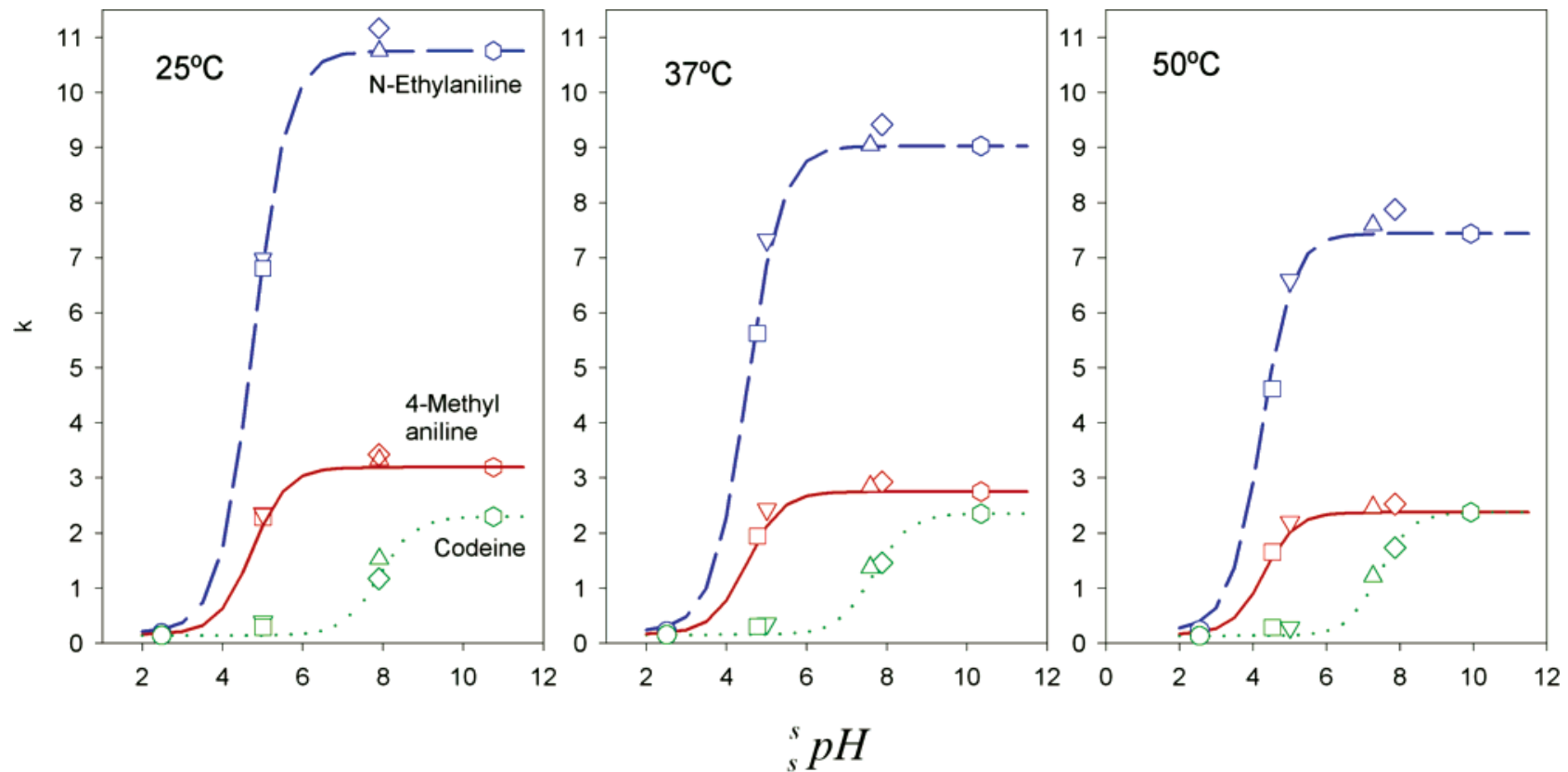

Figure 2. Predicted and experimental retention factors of three amines as a function of ${ }_{s}^{\mathrm{p}} \mathrm{pH}$ at 25,37 , and $50^{\circ} \mathrm{C}$. Column, mobile phase, and symbols as in Figure 1.

and at three column temperatures. The input data for predictions were $k_{\mathrm{HA}}$ and $k_{\mathrm{A}}$ at the reference temperature, $\left(T_{\mathrm{r}}=25^{\circ} \mathrm{C}\right)$ and at the highest temperature of the studied range $\left(50^{\circ} \mathrm{C}\right)$ as well as the $\mathrm{p} K_{\mathrm{a}}$ and dissociation enthalpies of the buffer and of each analyte. These data were fitted to eq 15 and represented with lines. The points in the figure correspond to the experimentally measured retention factors in each buffer solution. Similarly, in Figures 2 and 3, we show the predicted and the experimental points representing retention factors of three representative amines ( $N$-ethylaniline, methylaniline, codeine phosphate) and three phenols (2-nitrophenol, 4-nitrophenol, 2,6-dinitrophenol), respectively. In these simulations, the data correspond to the solvent composition of $25 \%(\mathrm{w} / \mathrm{w})$ acetonitrile in water. A consequence of the behavior described by eq 15 is that significant changes in retention with $\mathrm{pH}$ do not take place for $\mathrm{pH}$ values out of the range of \pm 2 units from ${ }_{s}^{\mathrm{s}} \mathrm{p} K_{\mathrm{a}}$ of the analyte; i.e., the limiting retention factors $k_{\mathrm{HA}}$ and $k_{\mathrm{A}}$ are independent of both $\mathrm{pH}$ and also buffer chemical nature.

As can be observed in these figures, it is feasible to accurately predict the retention behavior of all these solutes at any $\mathrm{pH}$ and 

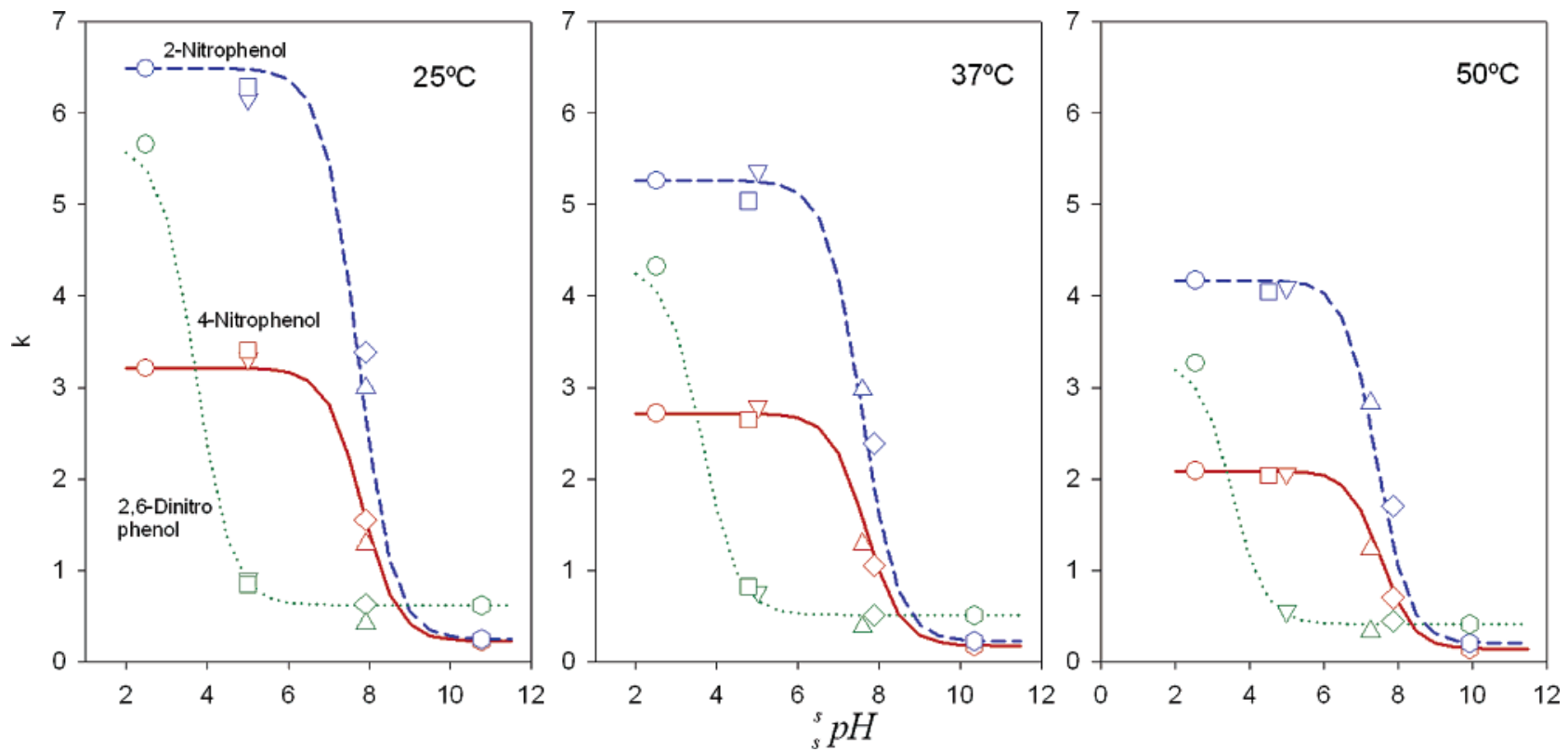

Figure 3. Predicted and experimental retention factors of three phenols as a function of ${ }_{\mathrm{s}}^{\mathrm{s}} \mathrm{pH}$ at 25,37 , and $50{ }^{\circ} \mathrm{C}$. Column, mobile phase, and symbols as in Figure 1.
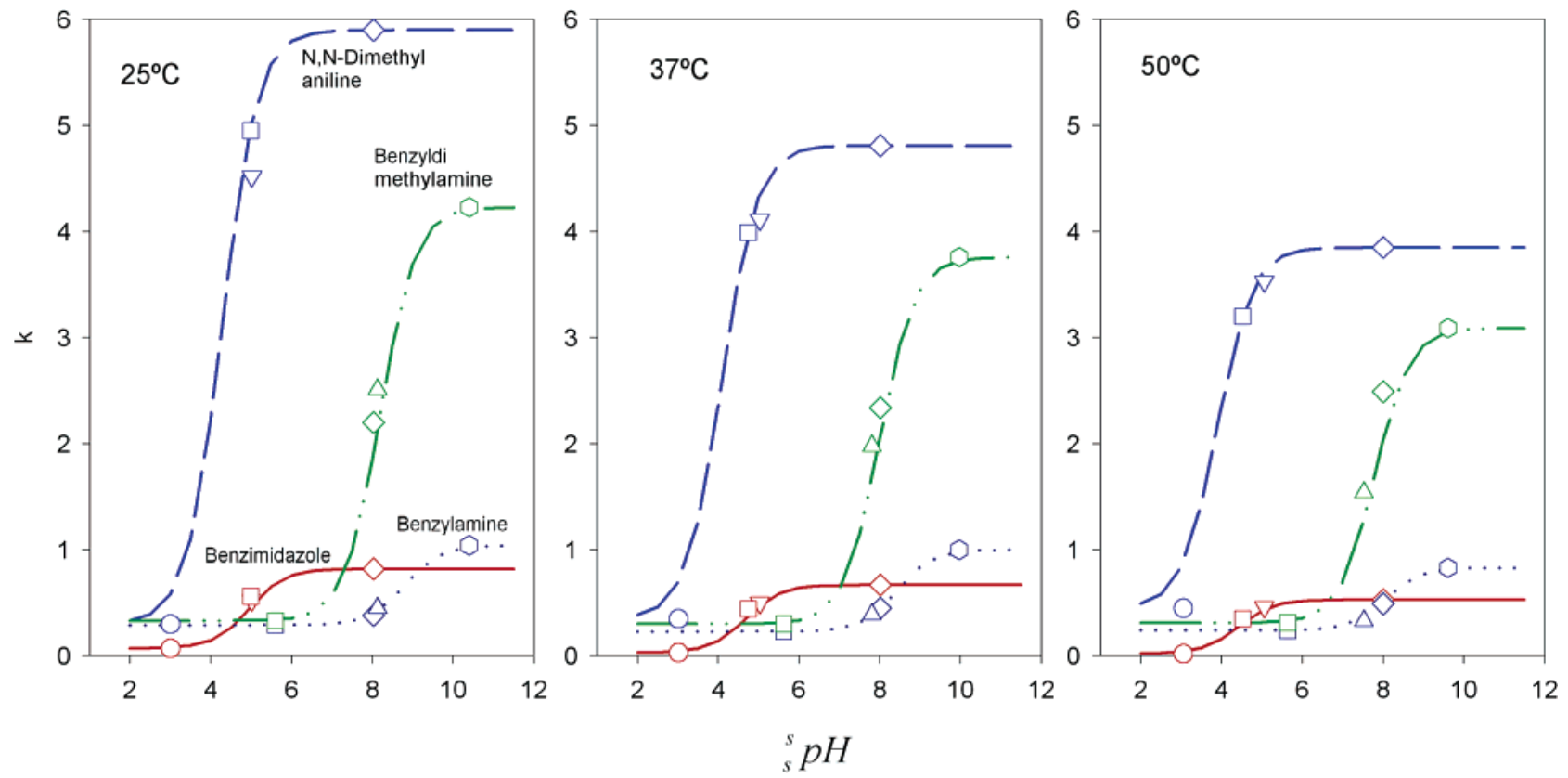

Figure 4. Predicted and experimental retention factors of four amines as a function of ${ }_{s}^{5} \mathrm{pH}$ at 25,37 , and $50{ }^{\circ} \mathrm{C}$. Chromatographic column as in Figure 1. Mobile phase: buffer solutions in $50 \% \mathrm{w} / \mathrm{w}$ methanol/water mixture. Symbols: circles, phosphoric acid/dihydrogen phosphate; triangles down, acetic acid/sodium acetate; squares, piperazine/hydrochloric acid; diamonds, dihydrogen phosphate/disodium phosphate; triangles up, tris/tris- $\mathrm{HCl}$; hexagons, butylamine/ $\mathrm{HCl}$.

any temperature within the range studied. The agreement between predicted and experimental data for mobile phases containing buffer solutions at intermediate $\mathrm{pH}$ is remarkable, even for those solutes that increase their retention when temperature increases in a given buffer solution. For instance, the three carboxylic acids in buffer piperazine (square symbols) or codeine phosphate in eluent containing phosphate buffer (diamonds), increase their retention factors between 25 and $50{ }^{\circ} \mathrm{C}$; the proposed model exactly predicts those temperature dependencies.

It is worth mentioning that no irregular solute peak shapes were detected when the solutes were analyzed in any mobile phase at a $\mathrm{pH}$ close to their corresponding $\mathrm{p} K_{\mathrm{a}}$, indicating that the ionization kinetics is significantly faster than the chromatographic partition process.

Figure 4 shows the plots resulting from modeling the retention behavior of four amines (benzimidazole, $N, N$-dimethylamine, benzylamine, benzyldimethylamine) as a function of eluent $\mathrm{pH}$ and column temperature in a solvent mixture containing $50 \%(\mathrm{w} / \mathrm{w})$ methanol. The points on the figures correspond to the experimental retention data. It can be noted that even the increased retention of benzylamine from $k=0.38$ to $k=0.49$ and of benzyldimethylamine from $k=2.20$ to $k=2.49$ in buffer 


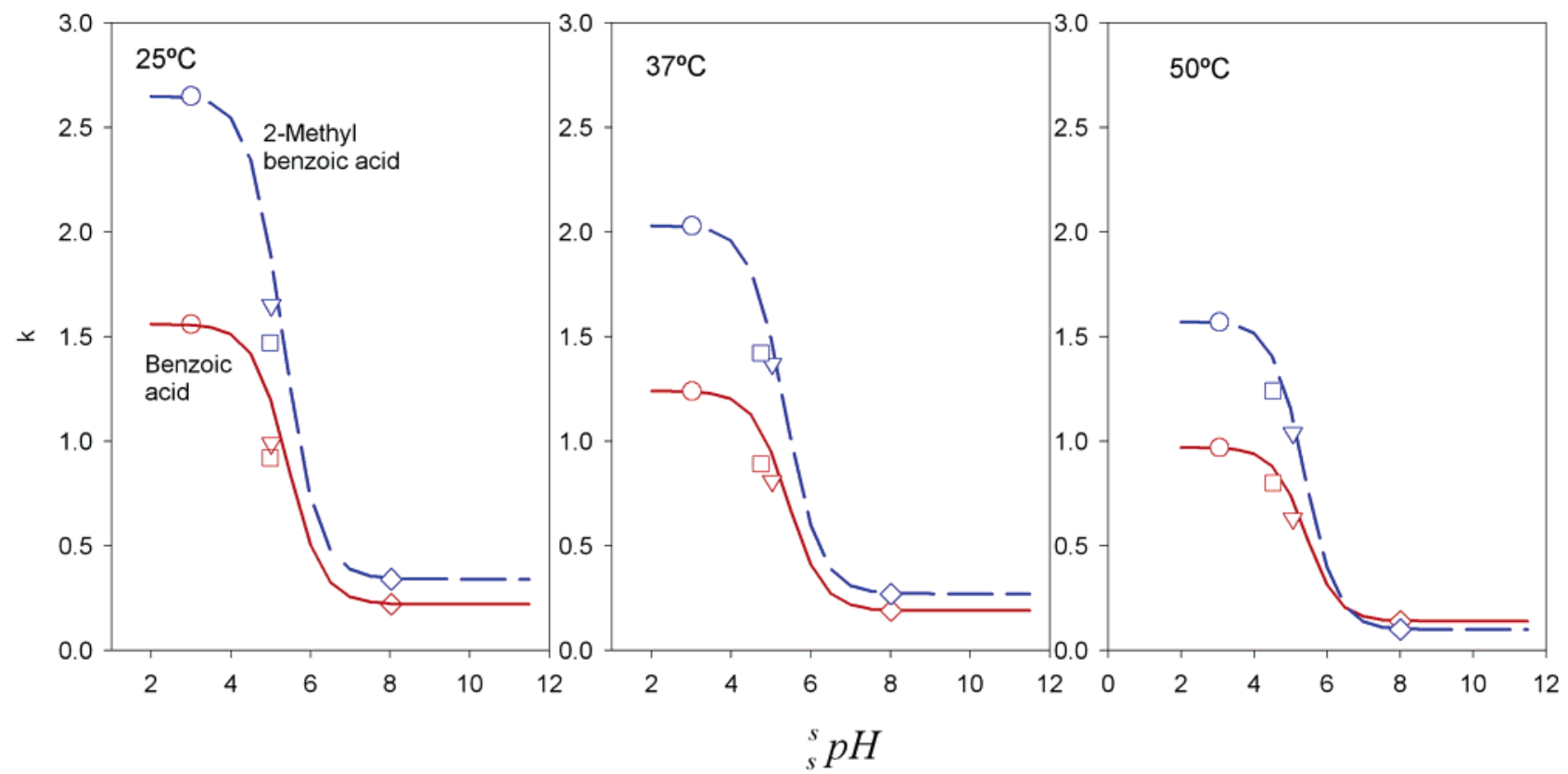

Figure 5. Predicted and experimental retention factors of two carboxylic acids versus ${ }_{\mathrm{s}}^{\mathrm{s}} \mathrm{pH}$ at 25,37 , and $50{ }^{\circ} \mathrm{C}$. Column, mobile phase, and buffer symbols as in Figure 4.
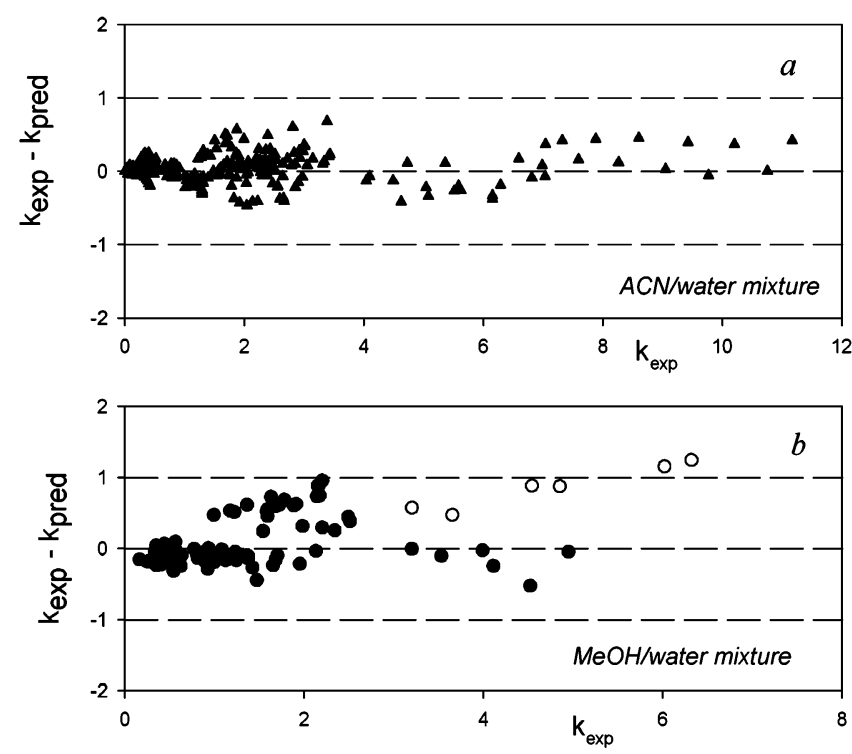

Figure 6. Accuracy in the predicted retention factors for all the solutes according to eq 15 . Residuals between predicted and experimental $k$-values in mobile phase acetonitrile/buffer (plot a) and in methanol/buffer eluent (plot b). Open circles in plot b correspond to predictions for 2,4-dichlorophenol.

phosphate as temperature increases between 25 and $50{ }^{\circ} \mathrm{C}$ (diamond symbols) are correctly predicted. Figure 5 shows the estimated curves of $k$ versus $\mathrm{pH}$ of benzoic and $o$-toluic acids.

The errors associated with the fitting are represented in Figure 6 , where residuals between observed and predicted $k$-values at all temperatures are plotted against the experimental data. It can be noted that the predictions were certainly more accurate for acetonitrile/buffer mixtures. The larger difference between predicted and experimental data was $+0.68 k$-units and only two other solutes exhibited absolute residuals above $0.5 k$-units in plot a (acetonitrile solvent mixtures). In plot b (methanolic solvent mixtures) data corresponding to 2,4-dichlorophenol were indicated with open circles. Predictions for this solute were hardly $1-k$ unit smaller than experimental observed values. Residuals between 0.5 and $1 k$ unit were obtained for only two other solutes, trazodone and 2,6-diclorophenol in this methanol/buffer mobile phase. Larger residuals were obtained for the amino acids 3 - and 4-aminobenzoic acids, but these are diprotics and an extended form of eq 15 had to be used. All other values obtained from using the proposed model were less than $0.5-k$ units apart from the experimental data. It has to be highlighted that the all the estimations require only four chromatographic experiments: retention of analytes in two buffers at extreme $\mathrm{pH}$ and each of them at only two column temperatures.

A reversed approach has been tested too. One may start from eq 15 and, including the enthalpies reported in last columns of Tables 1 and 2, allow the factors therein $\left(\mathrm{p} K_{\mathrm{a}}\left(T_{\mathrm{r}}\right), k_{\mathrm{HA}}\left(T_{\mathrm{r}}\right)\right.$, and $\left.k_{\mathrm{A}}\left(T_{\mathrm{r}}\right)\right)$ to be adjustable coefficients of experimental $k$ versus $\mathrm{pH}$ and temperature. Thus, from experimental retention data at any $\mathrm{pH}$ and temperature, the dissociation ${ }_{\mathrm{s}}^{\mathrm{s}} \mathrm{p} K_{\mathrm{a}}$ in $25 \%$ (w/w) acetonitrile and in $50 \%(\mathrm{w} / \mathrm{w})$ methanol/water mixtures at $25^{\circ} \mathrm{C}$ has been calculated by minimizing the sum of the squared differences between observed and predicted values through an iterative calculation. The chromatographic ${ }_{\mathrm{s}}^{\mathrm{s}} \mathrm{p} K_{\mathrm{a}}$ values and also the difference from the those collected from the literature are reported in Table 2 .

The agreement between chromatographically measured data and those collected from the literature is quite good. When acetonitrile is used as organic modifier, the agreement between the ${ }_{\mathrm{s}}^{\mathrm{s}} \mathrm{p} K_{\mathrm{a}}$ values obtained chromatographically and those from the literature is remarkable, and also the precision of the estimated ${ }_{\mathrm{s}}^{\mathrm{s}} \mathrm{p} K_{\mathrm{a}}$ is good. Somewhat poorer precision and greater residuals were obtained for the substances analyzed in the methanolic mobile phases (see Table 2); two possible reasons can explain this difference. The first one is that each ${ }_{\mathrm{s}}^{\mathrm{s}} \mathrm{p} K_{\mathrm{a}}\left(25^{\circ} \mathrm{C}\right)$ value in $25 \%(\mathrm{w} / \mathrm{w})$ acetonitrile was estimated from measurements con- 
ducted with six mobile phases at five temperatures, whereas chromatographic ${ }_{\mathrm{s}}^{\mathrm{s}} \mathrm{p} K_{\mathrm{a}}$ in $50 \%$ (w/w) methanol was obtained from fitting only four mobile phases at three temperatures. The other possible cause of poorer precision and accuracy was the different experimental design for the determination of the limiting retention factors. With acetonitrile mobile phases, the extreme $\mathrm{pH}$ values (mobile phases $\mathrm{A}$ and $\mathrm{F}$ ) provided the retention factors of the completely protonated and dissociated forms, respectively, for all compounds. Consequently, the retention curves were well defined and the results satisfactory. On the other hand, the limiting retention factors in methanolic mobile phases for analytes with ${ }_{\mathrm{s}}^{\mathrm{s}} K_{\mathrm{a}} \sim 5$ were determined with the mobile phases $\mathrm{G}$ and $\mathrm{J}$, whereas those limiting retention for compounds with ${ }_{\mathrm{s}}^{\mathrm{s}} \mathrm{p} K_{\mathrm{a}} \sim 8$ were measured with mobile phases $\mathrm{K}$ and $\mathrm{N}$. Thus, the extreme $\mathrm{pH}$ values of the buffers were not sufficiently acidic or basic to ensure the fully ionized and neutral forms of these analytes (e.g., trazodone ${ }_{\mathrm{s}}^{\mathrm{s}} \mathrm{pH}=6.33$ cannot be fully protonated at ${ }_{\mathrm{s}}^{\mathrm{s}} \mathrm{pH}=$ 5.64). Note that estimations of ${ }_{\mathrm{s}}^{\mathrm{s}} \mathrm{pK}_{\mathrm{a}}\left(25^{\circ} \mathrm{C}\right)$ from chromatographic retention at different temperatures and $\mathrm{pHs}$ are beyond the purpose of this study; we only pretend to validate the scope of the proposed equations.

Modeling Selectivity. The ultimate aim is devoted to describe the changes in selectivity between pairs of analytes when the column temperature is modified. Again, in the following analysis, we assume that only small-size molecules are considered, that a single retention mechanism dominates, and that both enthalpies and entropies of transfer do not depend on temperature.

Changes in temperature can lead to changes in the $\mathrm{p} K_{\mathrm{a}}$ of solutes and buffer components. At a mobile-phase $\mathrm{pH}$ far from $\mathrm{p} K_{\mathrm{a}}$, these changes are generally insufficient to cause an appreciable change in the ionization state of the solute and then to cause important changes in retention. Under these conditions, it is expected to be a minor influence on selectivity. The relationship between the logarithm of the selectivity factor between two solutes and the inverse of temperature will be the difference in enthalpy interactions between these two analytes. If one considers that typical enthalpies of transfer are similar, and about -10 to -15 $\mathrm{kJ} / \mathrm{mol}$, the absolute value of the slope of $\ln \alpha$ against $(1 / T)$ would not be further than $(5 / R) K^{-1}$, where $R$ is the gas constant (expressed in $\mathrm{kJ} \cdot \mathrm{mol}^{-1} \cdot \mathrm{K}^{-1}$ ). Many authors have found that the influence of temperature is significantly smaller than that due to modifications in solvent strength for nonionizable compounds. ${ }^{42,43}$

However, if the mobile-phase $\mathrm{pH}$ is in the region of solute $\mathrm{p} K_{\mathrm{a}}$, appreciable differences in selectivity can result depending on temperature and chemical nature of the buffer components. Figure 7 summarizes some selected examples. In plot a, we show the selectivity factors between 3-bromobenzoic and cinnamic acids as a function of temperature using two different buffers in $25 \%$

(42) Boillet, D.; Poole, C. F. Analyst 1998, 123, 295-300.

(43) Chen, M. H.; Horváth, C. J. Chromatogr., A 1997, 788, 51-61.

(44) Larson, J. W.; Helper, L. G. In Solute-Solvent Interactions; Coetzee, J. F., Ritchie, C. D., Eds.; Marcel Dekker: New York, 1969; Vol. 1.

(45) Budavari, S., Ed. Merck Index, 12 ed.; Whitehouse Station, NJ, 1996.

(46) Tam, K.; Takacs-Novak, K. Anal. Chim. Acta 2001, 434, 157-167.

(47) Palm, V. Tables of Rate and Equilibrium Constants of Heterolytic Organic Reactions; Vinity: Moscow 1975-1976. Supplements, Tartu, Estonia, 19841985.

(48) Mason, S. F. J. Chem. Soc. 1958, 675-678.

(49) Ruiz, R.; Ráfols, C.; Rosés, M.; Bosch, E. J. Pharm. Sci. 2003, 92, 14731477.

(50) Sarmini, K.; Kenndler, E. J. Chromatogr., A 1999, 833, 245-259.
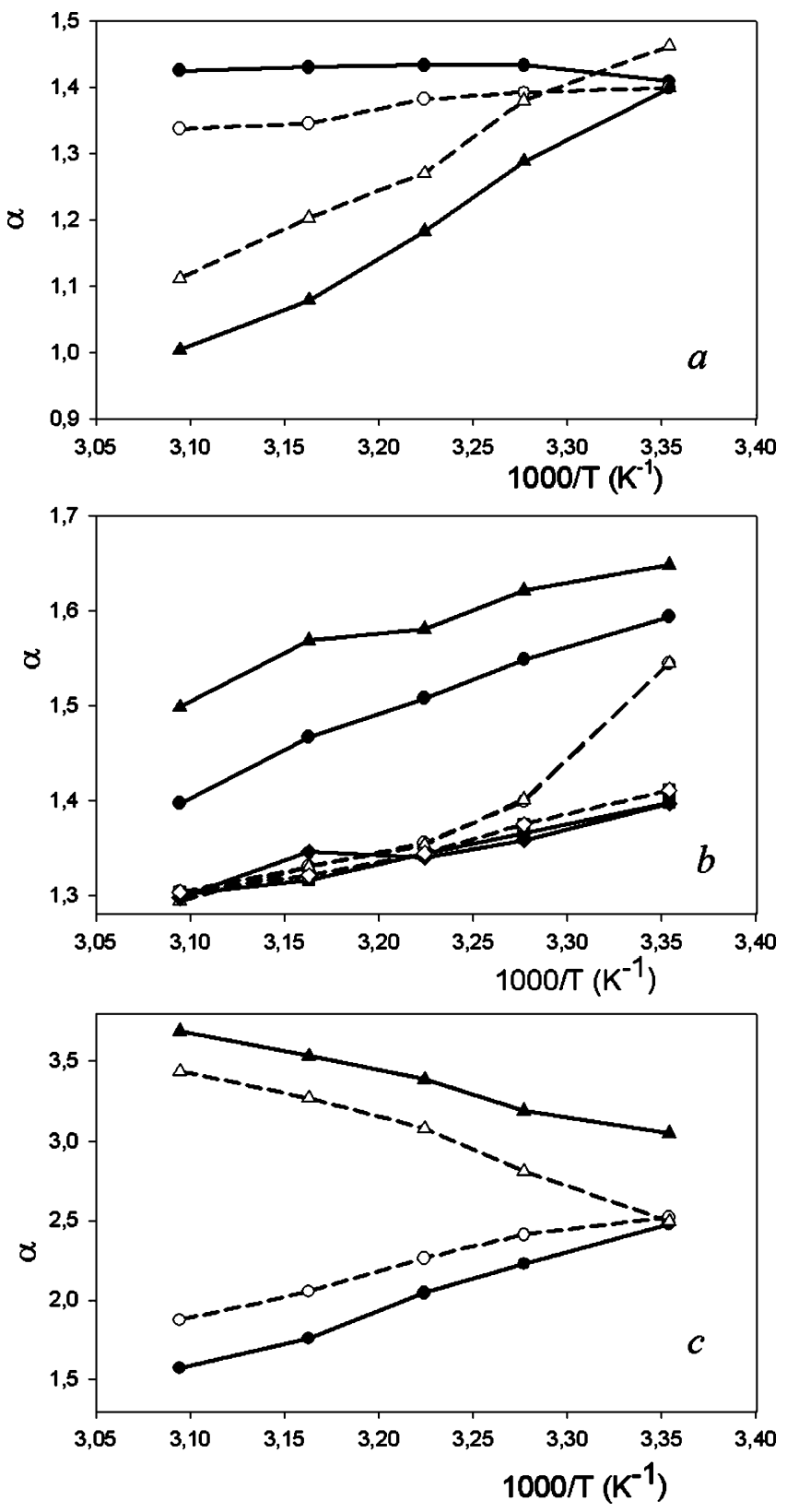

Figure 7. Selectivity factors against column temperature. (a) $\alpha$ (Cinnamic acid/3-bromobenzoic acid) in mobile phases $B$ (circles) and C (triangles). (b) $\alpha$ (4-Methylaniline/4-ethoxyaniline), mobile phases B (circles), C (triangles), D (squares), and E (diamonds). (c) $\alpha$ (4nitrophenol/2,6-dinitrophenol) in mobile phases $D$ (circles) and $E$ (triangles). Solid lines and full symbols correspond to experimental values; dotted lines and open symbols correspond to predictions.

(w/w) of acetonitrile mobile phase. Full symbols represent experimental selectivity factors whereas open symbols correspond to the predicted selectivity factors obtained from the ratio between theoretical retention factors. While the ${ }_{\mathrm{s}}^{\mathrm{s}} \mathrm{pH}$ of acetate (buffer B) remains constant over the temperature range, that of buffer $\mathrm{C}$ drops from 5.01 to 4.53 over the same temperature range. This change has a greater effect on 3-bromobenzoic acid, whose ${ }_{\mathrm{s}}^{\mathrm{s}} K_{\mathrm{a}}\left(25^{\circ} \mathrm{C}\right)$ is 4.56 compared to 5.19 for cinnamic acid. The $\mathrm{pH}$ shift of buffer $\mathrm{C}$ leads to an increase in the proportion of neutral 3-bromobenzoic acid and thus to the retention of this solute, compared with cinnamic acid, which is less affected. Figure $7 \mathrm{~b}$ shows the selectivity variation for the pair 4-methylaniline/4- 
ethoxyaniline in four buffered solutions. A decrease in selectivity is observed (and predicted) when temperature is increased from 25 to $50^{\circ} \mathrm{C}$ for any of these four buffered mobile phases. Finally, plot $\mathrm{c}$ depicts the dependence of selectivity between 4-nitrophenol and 2,6-dinitrophenol in two mobile phases with column temperature. These eluents were prepared by exactly matching their $\mathrm{pHs}$ at $25^{\circ} \mathrm{C}$; however, with phosphate buffer, $\alpha$-value decreases more than $35 \%$ when the column is heated from 25 to $50{ }^{\circ} \mathrm{C}$, whereas selectivity factors increase $\sim 20 \%$ for the same temperature range if phosphate is replaced with tris buffer. The agreement between predicted and experimental selectivity trends in the three examples compared in Figure 7 is remarkable.

Despite the possible deviations due to the assumptions described in the Theory section, eq 15 is a very good starting point for simple predictions of both chromatographic retention and chromatographic selectivity.

\section{CONCLUSIONS}

An accurate correlation between retention and the mobilephase $\mathrm{pH}$ at different temperatures, measured in the hydroorganic mixture, could be established, allowing prediction of the chromatographic behavior as a function of both variables: mobilephase $\mathrm{pH}$ and column temperature.

It is clear that the model, which is based on single thermodynamic functions dominating all the involved equilibria, is able to successfully describe chromatographic behavior of ionogenic compounds in purely RPLC systems. Relatively simple equations can be used to express the dependencies of retention factors and dissociation constants on the mobile-phase $\mathrm{pH}$ and temperature. When necessary, more sophisticated equations would be introduced into the model without affecting the main equations. The model predicts the dependence of the analyte retention factor on the mobile-phase $\mathrm{pH}$ regardless of the chemical nature of the buffer compounds.

The general eq 15 may be used also to obtain the dissociation constants $K_{\mathrm{a}}$ of monoprotic acids and bases at any temperature. This may be accomplished by a nonlinear fitting of $k$-data at various pHs and under a given temperature to the equation.

\section{ACKNOWLEDGMENT}

We are thankful for financial support from the Spanish Government (Project CTQ2004-00633/BQU) and C.B.C. acknowledges Fundación Antorchas (Argentina), IFS (Sweden), and CONICET (Consejo Nacional de Investigaciones Científicas y Técnicas, Argentina) for their support.

Received for review March 16, 2006. Accepted June 6, 2006.

AC060482I 